\title{
Salvador Rueda: teoría y práctica del Modernismo
}

\author{
GuIllermo CARNERO \\ Universidad de Alicante
}

La obra de Salvador Rueda constituye uno de los universos más extensos, variopintos y sorprendentes que pueda ofrecer la historia de las Letras españolas, y adentrarse en él es una aventura insólita y verdaderamente estimulante para todo aficionado a la literatura finisecular. Es una lástima que no esté todavía a nuestro alcance la edición que mi buen amigo el profesor Cristóbal Cuevas, catedrático de la Universidad de Málaga, ha preparado, y que será una verdadera revelación cuando aparezca $(*)$. Aunque nada es comparable al placer de acariciar y oler las primeras ediciones amarillentas y recorrer sus páginas de tipografía arcaica, dejando a un lado la utilidad profesional - y nuestra actividad, más que profesión, es lujo del espíritu y manía de coleccionista.

(*) Este estudio se redactó en septiembre de 1985, con destino al Congreso Internacional sobre el Modernismo español e hispanoamericano celebrado en Córdoba en el siguiente mes de octubre. En el momento de darlo a imprenta llega a mis manos la esperada edición de Cristóbal Cuevas: Salvador Rueda, Canciones y poemas, Madrid, Fundación R. Areces, 1986. En su extenso y documentado prólogo de 130 páginas Cristóbal Cuevas traza la biografía personal y literaria de Rueda y estudia su ecumenismo temático (multiformidad de la Naturaleza desde lo ciclópeo a lo diminuto, erotismo cósmico, conquistas de la ciencia y la técnica, españolismo y regionalismo andaluz), su estilo y teoría poética (sensorialismo, sinestesia, metaforismo, léxico y neologismo, adjetivación, ritmo, métrica, rima, estrofa), su relación con 
Existen numerosos síntomas, desde fines del XIX, de interés y aprecio hacia la obra de Rueda. En 1891 ve la luz un librito de tono cordial y encomiástico: Salvador Rueda y sus obras, de Gabriel Ruiz de Almodóvar ${ }^{1}$. El autor alaba la espontaneidad, la capacidad de captación del matiz, el «sentimiento innato de la forma» ${ }^{2}$ y el rico y precioso vocabulario de Rueda; lo defiende de las acusaciones de amaneramiento y neogongorismo y pone en su haber la maestría en lo descriptivo, la emoción ante la Naturaleza y la recreación del ambiente espiritual de Andalucía. En 1894 aparece un libro de inmaduros poemas titulado Tristes $y$ alegres ${ }^{3}$. Sus autores se llaman Manuel Machado y Enrique Paradas. Olvidemos a Paradas para fijarnos en este Machado de veinte años. Es aún un poeta de aluvión y sumamente mimético: traiciona lecturas no asimiladas de Espronceda, Quintana, Bécquer, Campoamor, Zorrilla y, naturalmente y sobre todo, Salvador Rueda. Escribe sonetos, romances, coplas y hasta tercetos encadenados ${ }^{4}$. Entre los ecos becquerianos ${ }^{5}$, campoamorianos ${ }^{6}$ y zorrillescos ${ }^{7}$ hallamos dos registros que sin duda proceden de Rueda: las coplas popularistas salpicadas de coloquialismo y vulgarismo, y los temas enlazados de la metrópolis moderna y el progreso científico ${ }^{8}$ : todo ello ha podido aprenderlo en Renglones cortos (1880), Noventa estrofas y Cuadros de Andalucía (1883), Estrellas errantes (1889), Cantos de la vendimia (1891) y En tropel (1892), libros que además pudieron proporcionarle influencias de segunda ma-

Rubén y el Modernismo y su influencia (Villaespesa, Manuel Machado, Juan Ramón, Lorca, Alberti, Gabriel Miró, Dámaso Alonso). Sigue una selección poética de mil páginas. Gracias a esta edición ha dejado Salvador Rueda de ser un arcano para los estudiantes y lectores españoles, aunque el necesario proyecto de unas Obras Completas haya quedado una vez más aplazado, ante las dificultades que señala Cuevas y que todo estudioso de Rueda conoce.

1 Madrid, Tipografía M. G. Hernández, 1891, 48 pp.

2 Op. cit., pág. 16.

3 Tristes y alegres. Colección de poesías con una contera de Salvador Rueda, Madrid, Impta. y Litografía La Catalana, 1894. Las composiciones de los dos autores van por separado.

4 Véase la «Epístola al eminente poeta el general don Vicente Riva Palacio».

5 «Reflejo», «¿No más?», «AAh!», «Fue», «El viento»...

6 «Realidad», «Así fue», «¿Por qué?»...

7 «Dormida», «El rescate»...

8 «Al día», «A mi querido hermano Pepe...» 
no de Campoamor, Núñez de Arce y Zorrilla. Acaso leyera también el joven Machado el Don Ramiro de Rueda ${ }^{9}$, leyenda al modo romántico cuyas fuentes se confiesan en la estrofa $X$ de su página 12:

De venganza en vil rencilla

y siempre en constante rueda, era el Félix de Espronceda

y el Tenorio de Zorrilla.

Rueda puso al tomo de Machado y Paradas una contera o epílogo: la modestia del título no le impidió declarar que los dos jóvenes poetas lo consideraban su maestro, ni ver en su cultivo de la copla popular (al que Rueda se adhiere en lo que ello tiene de oposición a la poesía preciosista y pomposa) una prueba de ese magisterio, con el que cualquier lector de Tristes y alegres estará de acuerdo.

En 1900 aparece Piedras preciosas de Rueda ${ }^{10}$ con un prólogo de Gregorio Martínez Sierra, de cuyo entusiasmo dan fe los fragmentos siguientes:

Después de mi estática [sic] contemplación [de los versos de S.R.], al apartar los ojos del luminar radiante, toda la tierra me parecía muerta: no había ya colores.

¡Sus sonetos! Poemas tallados en un solo diamante y ceñidos por orla de claveles.

La grey poética de España, saturada de versos quintanescos, hastiada del artificio, al iniciar él la poesía de la vida, de la verdad, del alma, se lanzó arrebatada en seguimiento suyo como enjambre de mariposas que se precipita sobre la luz.

Poco después, en Alma Española de 7 de febrero de 1904 («De la juventud»), Martínez Sierra defenderá a Rueda y Rubén de los ataques de Emilio Bobadilla en la misma revista ${ }^{11}$.

9 Don Ramiro. Cuaderno tercero. Madrid, Lib.as M. Murillo \& F. Fe, 1883.

Madrid, Impta. E. Rojas, 1900.

G. Martínez Sierra, «De la juventud», Alma Española 7-2-1904, pp. 10 y 11 . Véase E. Bobadilla, «Desde mi celda», ibíd. 8-11-1903, pág. 10. Según Fray Candil, la crítica no sirve más que para lisiar de vez en cuando a un poeta ripioso como Rueda. Arremete asimismo contra Rubén y los modernistas en general, a los que llama «hijos degenerados de Góngora», oscuros, alambicados y laberínticos. Utilizo el facsímil Madrid, Turner, 1978. 
En 1906, en el prólogo a Fuente de salud ${ }^{12}$, Unamuno destacará el vitalismo de Rueda. La aparición de Trompetas de órgano ${ }^{13} \mathrm{da}$ lugar a sendas críticas en La Lectura y Nuestro Tiempo, debidas respectivamente a J. Martínez Albacete y E. Ramírez Angel ${ }^{14}$, en las que se destaca el panteísmo, vitalismo y luminosidad del malagueño, su independencia de «la moda parisiense» y su influencia en españoles y latinoamericanos. Martínez Albacete repara en algunos prosaísmos disculpables; volveremos sobre ello.

Trompetas de órgano se publicó con preliminar de Manuel Ugarte. El argentino, campeón de la unión de Hispanoamérica de acuerdo con el pensamiento de Bolívar y autor de EI porvenir de América Latina y $E l$ destino de un continente, señala que asombrar al lector con rarezas rebuscadas es propio de poetas menores, mientras los grandes están arraigados en la Naturaleza y la humanidad, como Rueda, poeta sencillo y sincero, de emoción elemental y raíz popular. Ugarte denuncia la injusticia cometida con Rueda por quienes no quieren reconocerlo como renovador de la poesía española e hispanoamericana; y la acusación parece dirigida contra los Modernistas, ya que habla de una escuela que pretendió volver la espalda al público y refugiarse en la excentricidad:

Los que anclaron hace quince años en una modalidad artificial y creen poseer aún el secreto de la última moda podrán, cediendo a un sectarismo lamentable, reprochar a este poeta su emoción humana y su plena luz.

Ugarte insiste en estas ideas al publicar un año después, en 1908, Las nuevas tendencias literarias ${ }^{15}$. El prefacio repudia el decadentismo, la oscuridad y el culturalismo, reclamando el uso de materiales autóctonos y la exteriorización del alma nacional latinoamericana. El arte americano y americanista ha de ser sencillo y accesible, como corresponde a los jóvenes y aurorales pueblos latinoamericanos, que en su cultura poco refinada y nada aristocrática son todo lo contrario de un fin de race, leemos en el capítulo «La orientación actual». Y en el titulado «Una

12 Madrid, Impta. J. Rueda, 1906.

13 Madrid, Impta. P. Fernández, 1907.

14 «Trompetas de órgano, colección de poesías de Salvador Rueda...», La Lectura, año VII, tomo II, 1907, pp. 192-195; «Trompetas de órgano, último libro de poesías de Salvador Rueda», Nuestro Tiempo, n. ${ }^{\circ} 91$, 10-1-1907, pp. 83-87.

15 Valencia, F. Sempere y Cía., s. a. (1908). 
ojeada sobre la literatura hispanoamericana» se denuncia la «epidemia de parnasianismo» y se pide a la juventud literaria que olvide «el apego a los temas exóticos, la indiferencia ante la vida». El arte nacional exigido por Ugarte ha de basarse en la Naturaleza, los tipos humanos y los problemas de América Latina, sin caer en los tópicos gauchescos:

No hay razón para que la literatura siga siendo exótica cuando tenemos territorios, costumbres y pensamientos que nos pertenecen [...] Nuestro pequeño caudal de aguas tiene que buscar lecho propio, en vez de sacrificarse y fundirse en el de los grandes ríos; y las producciones nacidas dentro de las fronteras han de llevar un sello claro que las denuncie ${ }^{16}$.

Años después, $y$ en la pluma de Blanco-Fombona ${ }^{17}$, esta reclamación de un arte nacional hispanoamericano va a traducirse en acusaciones explícitas contra Rubén Darío. En los textos de Ugarte que comentamos está claro que frente a un Modernismo acusado de afrancesado, alquitarado y extranjerizante, Salvador Rueda aparece como paradigma digno de ser imitado, mutatis mutandis, en la América hispana. Carece en cambio de tono polémico la semblanza de Rueda que hallamos en Visiones de España ${ }^{18}$ del mismo Ugarte: un compendio de retratos de escritores del momento (Valera, Galdós, Blasco Ibáñez, Dicenta) y de impresiones sobre tierras, ciudades y cuestiones españolas.

Este año de 1908 es rico en trabajos dedicados a Rueda. Augusto Martínez Olmedilla publica un folleto de 15 páginas titulado Salvador Rueda. Su significación, su vida, sus obras ${ }^{19}$. Rueda, a este lado del Atlántico, es también bandera de nacionalismo literario; para Olmedilla su mérito está en haber logrado atraer a los poetas hispanoamericanos que se descastellanizaban por influjo de Verlaine y Baudelaire. Define al poeta malagueño como un místico de tres grandes temas, Dios, el hombre y la Naturaleza, y recalca sus innovaciones métrico-estróficas y su espontaneidad:

Espíritu sencillo el suyo, sin reconditeces laberínticas, diáfano como si formado estuviera de gotas de rocío escanciadas en trasparente cristal de Bohemia, antes de cuajar su pensamiento en poesía penetra muy de mañana en el Jardín de las Musas, coge febrilmente grandes brazadas de flores, silves-

16 Op. cit., p. 22.

17 Rufino Blanco-Fombona, El Modernismo y los poetas modernistas, Madrid, Mundo Latino, 1929.

18 Valencia, F. Sempere, s.a. (1904); «Salvador Rueda» en pp. 111-114.

19 Madrid, G. Pueyo, 1908. 
tres las más de ellas, aún esmaltadas por el húmedo beso de la noche, y las arroja pródigo a la turba de sus admiradores, que, hechas versos, las absorben con delicia ${ }^{20}$.

El año 1908 ve la luz un libro dedicado casi íntegramente a Rueda a pesar de su título: Los grandes maestros. Salvador Rueda y Rubén Darío, de Andrés González-Blanco ${ }^{21}$. Obra extensa y de subidas pretensiones estéticas y filosóficas, toda ella un canto al autor de En tropel. Según el autor, la poesía de Rueda es «poesía de sangre, poesía española, trágica, ardiente, más berebere que culta» ${ }^{22}$-ya veremos cómo otros usarán el término berebere en muy distinto sentido-. Estamos ante «un poeta colorista, un poeta pintor, un poeta de lo externo» que al tiempo es «un lírico de los combates interiores, un cantor de las luchas del alma» ${ }^{23}$, más parnasiano que simbolista: en lugar de lo impreciso y lo subconsciente «ama los trazos gráficos, los contornos netos, las construcciones amplias, las estrofas onduladas y magníficas, las rimas raras» ${ }^{24}$. Un poeta de multitudes, no de torre ebúrnea.

Ha renovado la métrica española tras Espronceda y Zorrilla; en ello le corresponde el primer puesto, antes que a Rubén, por razones de cronología, aunque éste llegara más lejos en otros ámbitos:

Rueda fue en verdad el Mesías de la poesía española que surgió hacia el año 85 para salvarnos de las rutinarias odas quintanescas y de la zafia imitación de los campoamorianos [...] Después vino el otro maestro, el gran Rubén, elegido por Dios para recoger la herencia del primero y acrecentarla con su tesoro nuevo. ${ }^{25}$

Rueda -y en menor medida Gil y Reina - llenan para GonzálezBlanco la etapa poética española 1885-1900. El autor nos pide que la prioridad indiscutible de Rueda no se traduzca en menosprecio del gran Rubén, por medio de una imagen de tan exquisita cursilería que no me resisto a transcribirla:

\footnotetext{
20 Op. cit., pág. 4.

21 Madrid, Pueyo, 1908.

22 Op. cit., pág. 5.

23 Ibid., pág. 18.

24 Ibíd., pág. 26.

25 Ibíd., pág. 109.
} 
Los nombres de los dos altísimos poetas pueden muy bien ir enlazados como iniciales de una sábana conyugal, donde se entrelazan a la vez las letras y los ensueños ${ }^{26}$.

Y también en 1908 epiloga Curros Enríquez Lenguas de fuego ${ }^{27}$ en unión de una de esas sartas de reseñas periodísticas y frases elogiosas con las que se complacía Rueda en cerrar sus libros, y afirma que Rubén, en detrimento de su originalidad, se benefició de la influencia de Rueda. Las Completas de Maucci aparecen con prólogos del mismo Enríquez (para quien Rueda es «el primero de nuestros poetas vivos») y del vicepresidente cubano Zayas, y con un sustancioso epílogo ${ }^{28}$.

Resulta de todos estos testimonios que, a comienzos de este siglo, estaba ya firmemente arraigada, a ambos lados del océano, la tesis de la precedencia de Rueda sobre Rubén en materia de renovación de la poesía en lengua castellana; tesis a la que se incorporaron aquellos hombres de letras hispanoamericanos que veían en la actitud de Rueda un antídoto contra la falta de dimensión americana de la obra de Rubén. Son años de triunfo para Rueda. El hispanista Camille Pitollet le dedica un estudio en Hispania ${ }^{29}$. Recibe los homenajes de Murcia, en 1902, y Albacete y Alicante en 1908, incluyendo el de esta última ciudad una lírica «Ofrenda» de Gabriel Miró aparecida en primera página del Diario de Alicante de 21 de mayo ${ }^{30}$; y posteriormente los de La Habana (1910), Buenos Aires (1913) y Manila (1915). La otra cara de la moneda es la actitud antimodernista de Bobadilla, Clarín, Ferrari, Maeztu, Ortega, Unamuno o Valera, documentada extensamente por el profesor

Ibíd., pág. 297.

Madrid, Impta. J. Rueda, 1908.

Poesías completas, Barcelona, Maucci, s. a. (1910). «Prólogo» de M. Curros Enríquez, pp. V-VIII; «Discurso pronunciado por el Doctor Alfredo Zayas...», pp. 9-15; «Discurso leído por el doctor Fernando Sánchez de Fuentes...», pp. 519-526, etc.

«En marge des Poesías completas», Hispania, 1911, pp. 217-260. No he podido verlo.

V. Ramos, Gabriel Miró, Alicante, Instituto Estudios Alicantinos, 1979, pp. 131-142. Véanse: El clavel murciano, Murcia, Impta. J. Perelló, 1902, y Salvador Rueda en Filipinas, Jornadas de poesía y patriotismo, Manila, Casino Español, 1915. En el primero, tras una serie de poemas de Rueda, sonetos en su mayor parte, dedicados a la ciudad en agradecimiento al nombramiento de hijo adoptivo, viene una corona literaria de discursos y poemas. El segundo contiene una crónica de las actividades de Rueda y los agasajos que recibió, más un apéndice documental de discursos, poemas y crónicas periodísticas. 
Martínez-Cachero ${ }^{31}$. El caso de Clarín es especialmente sintomático; de entre los escritos que dedicó a Rueda destacaré su artículo en dos partes aparecido en Madrid Cómico de 23 y 30 de diciembre de 1893. Para el zumbón y malévolo crítico, Rueda resulta amanerado; su andalucismo lo es «de exposición universal, de opereta», aunque «tiene el don precioso del ritmo» y acierta algunas veces, a pesar de su desbordante facilidad ${ }^{32}$.

En 1923 publica Enrique Díez-Canedo en España de 21 de julio su artículo «Los comienzos del Modernismo en España», estudio de gran importancia a pesar de su brevedad. Comienza declarando que no es justo hacer partir de la nada, en América y España, la obra de Rubén. En América hay que destacar a Martí y Gutiérrez Nájera. En España, a la hora de fijar una reacción contra los epígonos de Bécquer, Campoamor y Núñez de Arce, debe partirse de un tímido innovador, Eusebio Blasco, y de Rosalía de Castro, Ricardo Gil, Manuel Reina y Salvador Rueda. La significación de este último se debe a haber sido el único renovador, en sentido amplio y sistemático, de la métrica. El pensamiento de Canedo y González-Blanco se recoge en la tesis doctoral de José F. Montesinos, Die moderne Spanische Dichtung, de $1927^{33}$.

Sin valor crítico y repleta de extravagancias, incluso ortográficas, la Historia crítica del Modernismo de R. D. Silva Uzcátegui ${ }^{34}$, aparecida en 1925, se ocupa ocasionalmente de Rueda. El autor fue un adicto a las teorías de Lombroso y Nordau, y desde ellas nos ofrece una retrógrada psicopatología del Modernismo, asestada contra Baudelaire, Huysmans, Wilde, Whitman, Verlaine, Mallarmé, Moréas, Verhaeren, Rimbaud, Lorrain y, naturalmente, Rubén:

31 «Algunas referencias sobre el antimodernismo español», Archivum 1953 pp. 311-333; «El antimodernismo del poeta Emilio Ferrari», ibíd., 1954, pp. 368-384; «Más referencias sobre el antimodernismo español», ibíd., pp. 131-135; «La actitud antimodernista del crítico Clarín», Anales de Literatura Española Universidad de Alicante, 1983, pp. 383-398.

«Vivos y muertos. Salvador Rueda. Fragmentos de una semblanza», Madrid Cómico n. ${ }^{\circ} 566,23-12-1893$, pp. 3-4, y n. ${ }^{\circ} 567,30-12-1893$, pág. 3.

33 Berlín \& Leipzig, G. G. Teubner, 1927, cap. 2, pp. 24-28. Doy las gracias a mi buen amigo el profesor Klaus Pörtl, de la Universidad de Maguncia, por haberme conseguido una fotocopia de este raro impreso.

34 Historia crítica del Modernismo en la literatura castellana [...] Psicopatología de los corifeos del Modernismo, demostrada con los actos, las teorías, las innovaciones $i$ las poesías de ellos mismos [sic], Barcelona, Impta. Vda. L. Tasso, 1925. 
Es lógico que un neurótico alcoholizado como Rubén Darío y con un carácter tan extravagante sintiese un raro placer en hacer toda clase de innovaciones poéticas ${ }^{35}$.

Descubierta tan luminosa clave para explicar las novedades literarias como aberraciones mentales, pasa el autor revista a los hallazgos modernistas (y también, en el capítulo 4, al Futurismo y Cubismo), que desprecia olímpicamente contrastándolos con el ejemplar magisterio de Gabriel y Galán; y absuelve a Rueda de extravío de menor cuantía por no haber éste caído en las experimentaciones de Rubén con la cesura ${ }^{36}$, justamente lo que después notará, con otra intención muy distinta, Cossío.

La muerte de Rueda en 1933 provoca una oleada de estudios y artículos que aún no ha sido exhaustivamente catalogada. Destacaré cuatro de ellos por ser sus autores Juan Ramón Jiménez, Juan José Domenchina, Enrique Díez-Canedo y Narciso Alonso Cortés.

En El Sol de 9 de abril de 1933, página 2, publica Juan Ramón un artículo afectuoso titulado «Colorista español». Confiesa la deuda hacia Rueda de sus primeros poemas, habla del colorismo premodernista del malagueño y de Reina, señala que el primero cultivó el andalucismo que luego haría suyo Lorca, y que «en todos sus cantos tenía estrofas, versos sueltos, de rica belleza intuitiva» (Observemos que, discretamente, Juan Ramón Jiménez habla de aciertos aislados). Canedo, el 30 del mismo mes, misma página, en «Muere un poeta español. Salvador Rueda», insiste en el andalucismo popularista de Rueda vinculándolo al de los Machado y el primer Lorca, y con sobriedad apunta también la irregularidad y verbosidad del poeta recién fallecido.

Está claro que con el paso del tiempo la admiración hacia Rueda se ha ido templando. Han aparecido en escena escritores de mayor exigencia literaria. Domenchina, en su «Salvador Rueda», EI Sol, 16 de abril, página 2, formula el descenso de estimación hacia Rueda con cierta crudeza acaso poco oportuna:

Fue inicialmente -y auténticamente- Salvador Rueda un numen rústico, espontáneo, de entraña regional, extravasado o salido de madre por incontinencia retórica. El manadero humilde que pudo captar y fruir la belleza y la gracia del paisaje que le era propio osó precipitarse con hervor simulado de impetuoso caudal incoercible en el vacío seudosublime del énfasis, contra-

35 Op. cit., pág. 135.

36 Ibíd., pág. 269. 
haciendo la espectacular garrulería de una catarata ecuménica. En la aventura se perdió el acento, esto es, la realidad íntima de un poeta que pudo ser siendo sencillo, y emergió a su vera o costado un juglar de fragores, una musa estentórea: el vampiro de la celebridad tribunicia sobre los zancos alcornoqueños del inadmisible coturno [...] Hizo un cierto linaje de poesía al uso, de índole estrictamente prosaica [...] El brote poético surge y se consolida en él como a sus espaldas y dijérase que a su despecho [...] en cambio, al Salvador Rueda de la hipérbole se le encuentra en todas partes. Y es lástima, porque cuando Salvador Rueda, empinándose sobre sus zuecos infantiles (a los que él pretenciosamente da, como helénico, nombre de coturno) desemboca en la grandilocuencia tonitronante y vacua, su verbo gárrulo nos invade con el sopor y el agobio de una pesadilla diurna.

Ya en 1929, al reseñar E. Salazar Chapela la Antología poética de 1928 en La Gaceta Literaria (1 de marzo, página 3) hablaba de poesía fracasada y pomposa, aunque original en su momento y dotada de cualidades rítmicas. La admiración incondicional hacia Salvador Rueda había pasado a la Historia. Juan Ramón, Domenchina, Salazar Chapela o Canedo habían recibido el legado de una doble proclamación: la de la paternidad de Rueda con respecto al Modernismo, y la de su excelencia literaria; sin negar lo primero, fueron incapaces de asumir lo segundo. Este dilema explica aún hoy la singular actitud que ha de adoptar todo estudioso a la hora de valorar la obra de Rueda.

Seguimos en 1933. En Anales de la Universidad de Madrid. Letras va a aparecer el extenso estudio de Narciso Alonso Cortés «Salvador Rueda y la poesía de su tiempo ${ }^{37}$, recogido dos años más tarde por el autor en sus Artículos histórico-literarios ${ }^{38}$. Según don Narciso, Rubén y otros hispanoamericanos continuaron la reforma poética que ya se había iniciado en España, adornándola con ingredientes exóticos y llevándola a sus últimas consecuencias; pero no fueron agentes exclusivos de la transformación de la lírica española. Dominaban entonces en España y América del Sur Campoamor, Núñez de Arce y Bécquer; en una y otra se produjo similar reacción por obra de Ferrán, Bartrina, Eusebio Blasco, Manuel Reina, Rosalía de Castro, Ricardo Gil, Salvador Rueda, Gutiérrez Nájera, Julián del Casal, José Asunción Silva, Rubén. Con Sinfonía del año (1888) de Rueda se produce la primera manifestación clara de cambio de rumbos poéticos, tarea en la que el poeta malagueño no supo evitar la exageración, la irregularidad y las caídas en lo vulgar.

Vol. I pp. 71-92; II pp. 158-185

Valladolid, Impta. Castellana, 1935. 
Ya en la posguerra española, Cuadernos de Literatura Contemporánea dedica su n. ${ }^{\circ} 7$ (1943) a Rueda. Lo abre un soneto de Manuel Machado, «A Salvador Rueda, recordado en el albor de aquella nueva poesía española»; Juan Antonio Tamayo, en «Salvador Rueda o el ritmo», señala la abundancia del poeta de Benaque, conseguida en detrimento de la calidad ${ }^{39}$. En 1944 aparece el volumen II de la Galería de El Caballero Audaz, en la que figura una entrevista al poeta malagueño y otra a Rubén ${ }^{40}$. Dice el segundo:

He incorporado a la poesía española, que estaba detenida en Núñez de Arce, en Campoamor, en Rueda, una inquietud moderna... haciendo vivir al idioma dos fases que no conocía: el parnasianismo y el impresionismo simbolista... ${ }^{41}$.

Rueda, entre numerosas chuscadas (por ejemplo, que al volver a Málaga piensa dedicarse a vendimiar, empaquetar pasas y pisar uva), no da su brazo a torcer:

Aprovechando lo que había aprendido en la Naturaleza, de ella escribí las impresiones que fueron la base de la revolución de la lírica española ${ }^{42}$.

Carretero, por su parte, prefiere no entrar en la disputa:

Rueda, poeta grandilocuente, magnífico, era el heredero directo del glorioso autor de Las Orientales. Su poesía estaba empapada de luz, tenía centelleos de piedras preciosas, recamada [sic] de aljófares árabes, fuego de vino andaluz, y delicadezas de rosas de té ${ }^{43}$.

Guillermo Díaz-Plaja se ocupa de Rueda y otros artífices españoles del Modernismo en Modernismo frente a noventa y ocho (1951) ${ }^{44}$. Para Max Henríquez Ureña, según su Breve historia del Modernismo

39 Incluye también los artículos de N. Alonso Cortés «Armonía y emoción en Salvador Rueda», de Gerardo Diego «Salvador Rueda», de Juan Guerrero «Salvador Rueda en Tabarca» y de J.L. Cano «Recuerdo malagueño de Salvador Rueda», más una bibliografía preparada por J. Romo Arregui y una antología a cargo de Gerardo Diego. Véanse también los capítulos dedicados a Rueda en Poesía española del siglo $X X$ de Cano.

40 Galería. Más de cien vidas extraordinarias contadas por sus protagonistas..., Madrid, Eds. Caballero Audaz, 1944, pp. 323-329 y 27-31. Agradezco a mi querido amigo Andrés Amorós el haberme proporcionado este libro.

41 Op. cit., pág. 30.

42 Ibíd., pág. 325.

43 Ibíd., pág. 328.

Madrid, Espasa-Calpe, 1979, pp. 276-295. 
(1954) ${ }^{45}$, no cabe atribuir a Rueda ningún protagonismo en la génesis del movimiento. Radicalmente distinta es la opinión de Cernuda en sus Estudios sobre poesía española contemporánea (1957) ${ }^{46}$ : la obra de Reina, Gil y Rueda estaba ya cuajada cuando empezaron a leer a Rubén, y ha de hablarse de una doble génesis, española y americana, del Modernismo; aunque la obra de los españoles deje mucho que desear, escribe Cernuda, estamos ante «un modernismo español anterior e independiente del americano». En «Mementos de actualidad. Salvador Rueda» (Boletín de la Biblioteca Menéndez Pelayo, 1957, pp. 188-207), Enrique Sánchez Reyes publicó seis cartas de Pereda a Rueda y siete de éste a Menéndez Pelayo. La revista malagueña Caracola dedicó a Rueda su n. ${ }^{\circ}$ 62-63 (diciembre 1957-enero 1958) incluyendo artículos de José Luis Cano, Melchor Fernández Almagro, Vicente Núñez y Antonio Oliver. El último discute las conclusiones de Henríquez Ureña; Fernández Almagro y Núñez apuntan la influencia del poeta de Benaque en Lorca, Aleixandre y Cernuda; Cano trata de las relaciones entre Rueda y Juan Ramón. De las que unieron a Rueda y Rubén, y de la desviación antimodernista del primero se ocupa José M. ${ }^{a}$ Martínez Cachero en «Salvador Rueda y el Modernismo» (Boletín de la Biblioteca Menéndez Pelayo, 1958, pp. 41-61).

De 1960 son las páginas dedicadas a Rueda en el tomo II de Cincuenta años de poesía española ${ }^{47}$ de Cossío, donde se ponen en pie los pilares maestros del enjuiciamiento crítico de Rueda: herencia de Campoamor, andalucismo, naturalismo, innovaciones métricas:

Estas innovaciones métricas tuvieron precedentes notorios y Salvador Rueda puede justamente atribuirse el mérito de haber tenido conciencia de lo que significaban en la evolución retórica del verso. Pero esto no era lo central, ni aun en la métrica del modernismo que Rubén Darío fomentara. El verso de Rueda seguía teniendo la contundencia, el golpear seguro, el ritmo cuadrado del verso tal como entre los españoles se había cultivado siempre. En este sentido tiene razón Rubén Darío para atribuirse la iniciación de la verdadera revolución modernista. La influencia francesa hizo que Rubén tratara y lograra en cierto modo deshuesar el verso castellano, eliminar de él lo encorsetado y rígido, provocar la vacilación de su acento... ${ }^{48}$

45 México, F.C.E., 1962, pp. 35-42 y 510.

46 Madrid, Guadarrama, 1957, cap. «El Modernismo y la generación de 1898»; véanse pp. 73-78.

47 Madrid, Espasa-Calpe, 1960, 2 vols.; vol. II pp. 1330-1342.

Op. cit., pp. 1337-1338. 
Rueda resulta por ello ser para Cossío un innovador que precedió a Rubén, pero «un iniciador superado» ${ }^{49}$.

Rafael Ferreres dedicó a Rueda un breve artículo, «Diferencias y coincidencias entre Salvador Rueda y Rubén Darío» (Cuadernos Hispanoamericanos, enero 1964, pp. 39-44), reconociendo en Rubén mejor gusto literario y un helenismo más profundo. Carlos Edmundo de Ory («Salvador Rueda y García Lorca», Cuadernos Hispanoamericanos, marzo 1971, pp. 417-444) investiga la deuda hacia Rueda de la obra de Lorca hasta 1928, y la sistematiza (temática andaluza, microzoología antropomórfica, orientalismo de estirpe zorrillesca). En La Sinfonía del año de Salvador Rueda, folleto de Miguel d'Ors publicado en $1973^{50}$ tenemos un estudio de la cosmovisión de Rueda, de su estilo y su métrica. Bienvenido de la Fuente dedica en 1976 su tesis doctoral a Salvador Rueda, con el título de El modernismo en la poesía de Salvador Rueda ${ }^{51}$, el más extenso y sistemático estudio hasta ahora emprendido sobre el tema. De ningún valor crítico son los libros de M. Prados López El poeta de la raza Salvador Rueda, renovador de la métrica ${ }^{52}$ y D. Vázquez Otero Salvador Rueda ${ }^{53}$. Sin olvidar la Métrica española de Navarro Tomás ${ }^{54}$, quisiera terminar este repaso bibliográfico citando tres trabajos del profesor Richard Cardwell. Unas páginas de Juan Ramon Jiménez: The Modernist apprenticeship, 1895-1900 ${ }^{55}$ señalan que falta en Rueda la desazón y el pesimismo propios del talante espiritual finisecular, y sobra el «costumbrismo colorista». En «Rubén Darío y Salvador Rueda: dos versiones del Modernismo» (Revista de Literatura 89, 1983, pp. 55-72), el profesor Cardwell afirma que la religiosidad tradicional y conservadora de Rueda no encaja en el espíritu Modernista. Si bien ello es cierto estadísticamente, yo señalaría a mi admirado amigo que tres poemas de Rueda dan fe de una cierta inquietud religiosa con ribetes de heterodoxia: «La risa de Grecia» y «La fiesta

49 Ibíd., pág. 1342.

so Pamplona, EUNSA, 1973.

51 Berna \& Frankfurt, Lang, 1976.

52 Málaga, Diputación, 1967; con una primera edición en 1941 que no he visto.

53 Málaga, autor, 1960.

54 Madrid, Guadarrama, 1974, pp. 399 y ss.

55 Berlín, Colloquium, 1977, pp. 187-199. 
de las Palmas» en Fuente de salud, y «El triunfo de la flauta» en Trompetas de órgano. En el primero reivindica Rueda la alegria vital de la civilización griega, arrumbada por el Cristianismo; en el segundo reclama un Cristo de amor y bondad frente al sombrío Cristo del pecado y la penitencia; en el tercero anhela el retorno de la «interceptada vida» obstaculizada por las creencias religiosas. Hay pues en Rueda una veta ocasional de religiosidad más evangélica que eclesiástica, más vitalista que dogmática. En último lugar, citemos «Los albores del Modernismo...» del mismo Cardwell (Boletín de la Biblioteca Menéndez Pelayo, 1985, pp. 315-330) (**).

Salvador Rueda tuvo en su tiempo admiradores incondicionales y ha seguido teniendo turiferarios tras su muerte. En general se trata de un fenómeno de patriotismo local. Si atendemos a los testimonios responsables hemos de deducir que el poeta de Benaque fue una gran esperanza de la poesía española que se desvaneció en los últimos años del XIX y primeros del XX. Es de sobra conocido el artículo de Rubén Darío «Los poetas», aparecido en La nación de 1899 y luego en España contemporánea ${ }^{56}$. Es fácil interpretarlo como resultado de la envidia, el afán de protagonismo o lo que Cernuda llamaba «supervivencias tribales». Yo creo que Rubén tuvo toda la razón al declarar su decepción a propósito de la trayectoria literaria de Rueda. Y no fue el único. En su libro sobre Herrera y Reissig ${ }^{57}$ Villaespesa se refería despectivamente a «las sonoridades ensordecedoras y gárrulas a que tan aficionados son los oídos plebeyos y bereberes de Salvador Rueda»; Manuel Machado, en La guerra literaria, habla de fantasía exuberante, poderosamente instintiva pero a veces descarriada ${ }^{58}$. En la famosa "Enquête sobre el Modernismo» que va publicando El Nuevo Mercurio a lo largo de $1907^{59}$, Rueda es el gran ausente: sólo una referencia insustancial de

(**) Ya redactado este trabajo llega a mis manos la antología de Rueda preparada por R. Pérez Estrada con el título de Friso poético, Sevilla, Eds. Andaluzas Unidas, 1985.

56 España contemporánea, Madrid, Biblioteca Rubén Darío, OO.CC. vol. XXI, s. a., pp. 229-239; ver pág. 237.

57 Julio Herrera Reissig, Madrid, Impta. Helénica, 1911, pág. 18. Ed. M.P. Celma \& F. J. Blasco, Madrid, Narcea, 1981, pág. 108.

Marzo, pp. 335-342; Abril, pp. 398-407; Mayo, pp. 504-521; Junio, pp. 635-672; 
Manuel Machado ${ }^{60}$, un recuerdo de Manuel Ugarte ${ }^{61}$ y una censura de $\mathrm{R}$. Brenes a sus ideas sobre el ritmo ${ }^{62}$. Mi propósito en esta segunda parte de mi exposición será intentar explicar tales esperanzas y desencantos, con lo que podremos llegar a calibrar qué hay efectivamente de Modernismo en Salvador Rueda.

Modernismo es culto a la belleza y a la precisión en el uso de la palabra, reivindicación de la autonomía del lenguaje en su función estética, renuncia al utilitarismo docente, al realismo y al filosofismo prosaico en busca de un universo simbólico. Ello puede deducirse no sólo de la práctica literaria de los poetas indiscutibles del movimiento, sino de numerosas declaraciones teóricas: «El carácter de la Revista Venezolana» y «Óscar Wilde» de Martí ${ }^{63}$, «Parnasianos y decadentes» de Rubén ${ }^{64} \mathrm{o}$ «El arte de trabajar la prosa artística» de Gómez Carrillo en su libro El Modernismo ${ }^{65}$.

La práctica literaria de Salvador Rueda resultaba extraña a ese credo en numerosos puntos, y coincidía con él en algo que, aun siendo necesario, no pudo entonces ni puede ahora considerarse suficiente: el culto a la palabra. El lenguaje de Rueda es rico, brillante, sonoro, multiforme. Pero cinco limitaciones iban a deslucirlo, en lo que concierne al primer bloque de creencias modernistas que hace un momento ha quedado expuesto: la índole de su popularismo, un filosofismo prosaico y explícito, la persistencia de una superficial mitología rural, cierta sensiblería no contenida y reiterados disparates y muestras de mal gusto.

No pretendo decir que el mundo rural fuera un ámbito prohibido para los Modernistas: el caso de Juan Ramón lo negaría. Pero ese mundo aparece en Rueda como un popularismo costumbrista trasnochado y caduco. Veamos algunos ejemplos.

Julio, pp. 793-806; Agosto, pp. 886-894; Septiembre, pp. 1022-1025; Octubre, pp. 1137-1139; Noviembre, pp. 1248-1252; Diciembre, pp. 1423-1430.

Op. cit. pág. 339.

Ibíd., pág. 342 .

Ibíd., pág. 667.

Véase J. O. Jiménez (ed.), Antología crítica de la prosa modernista hispanoamericana, N. York, Eliseo Torres, 1976, pp. 45-46, y del mismo, J. Martí, Prosa escogida, Madrid, EMESA, 1975, pp. 59-70.

J. O. Jiménez (ed.), Antología crítica... pp. 52-53.

Madrid, Lib ${ }^{a}$ Española y Extranjera F. Beltrán, 1914. 
El poema «Una juerga» de Cuadros de Andalucía ${ }^{66}$ relata los amores de una manola y un chulapón, en un ambiente de bailongo y vinazo, con incrustación de diálogos de personajes del poema y de cantares populares; el tono costumbrista se persigue mediante descripciones de lo superficial y externo y recreación de la jerga coloquialista y avulgarada que supuestamente hablan las clases populares. Ello está a cien leguas de Baladas de primavera o de Platero y yo. En Estrellas errantes ${ }^{67}$ hallamos una colección de coplas populares del siguiente corte:

La Giralda de Sevilla
del sol poniente alumbrada
no despide tanta sombra
como tú de las pestañas.

El costumbrismo de Cuadros de Andalucía se encuentra asimismo en Poema nacional ${ }^{68}$, Cantos de la vendimia ${ }^{69}$ («En los olivares», «La caja de pasas», «La sequía»), En tropel ${ }^{70}$ («La gaita asturiana», «La herrada», «Los boquerones vitorianos», «El mantón de Manila»), Fuente de salud («La parranda triste», «La diligencia», «La pisa», «El pregón del pescado», «La danza del mosto»), Lenguas de fuego («La mujer andaluza», «El alma de Córdoba», «El molino»), Bajo la parra ${ }^{71}, E I$ país del Sol ${ }^{72}$ («El café de Zaragoza», «La romería de S. Isidro», «La fiesta de S. Antón»). Lo hallamos igualmente representado en la obra no poética de Rueda: El patio andaluz ${ }^{73}$ («El bautizo», «La parranda», «El lañador»), El cielo alegre ${ }^{74}$ («El baño de los chiquillos», «El sacorio», «Cuadro campestre», «El Doctor Centurias»), El gusano de

Cuadros de Andalucía. Cuaderno segundo, Madrid, Lib ${ }^{a}$ M. Murillo \& F. Fe, 1883.

67 Madrid, Tipogr. de El Crédito Público, 1889.

68 Poema nacional. I. Costumbres populares, Madrid, Tipogr. R. Fe. 1885.

69 Valencia, P. Aguilar, s. a. Primera edición en 1891, Madrid, Gran Centro Editorial.

70 2. ${ }^{a}$ edición, Madrid, Tipogr. M. G. Hernández, 1893.

71 Madrid, Impta. de La Gaceta Universal, s. a. (1897). Incluye prosas.

72 El país del Sol (España), Madrid, V. Díaz, s. a. (1901).

73 El patio andaluz. Cuadros de costumbres, Madrid, M. Rosado, 1886.

74 El cielo alegre. Escenas y tipos andaluces, $2 .^{\mathrm{a}}$ ed., Madrid, Administración de la Academia, 1887. 
Iuz ${ }^{75}$, La corrida de toros ${ }^{76}$, La reja ${ }^{77}$, Tanda de valses ${ }^{78}$ ( $« \mathrm{El}$ castillo de Santiago», «De tejas arriba», «La fuga del nido», «El baile de las nueces»), La vocación ${ }^{79}$, Donde Cristo dio las tres voces ${ }^{80}$ o La mu$\mathrm{sa}^{81}$. Un framento de El gusano de luz y la acotación inicial de La musa permitirán calibrar el populismo costumbrista de Rueda:

Zeñó, no me deje su merzé manca las parejas de bueyes, que con una ruea no anda un carro, y pa dos carros, dos parejas. Que no diga la moza que su merzé regatea lo que le da tanto del aquél y señorío por cima del que ella tiene, y se mira en la cifra cuando sólo debía mirarse en sus faicione. Parejas más desacordes que la de su merzé y la moza ha reunío Dios, y les ha echao las bendiciones. El hombre ha de tener años, porque con ellos viene la experiencia, y la mujé, que to es espuma y cosas delicás, nejecita de una mano que la guíe ${ }^{82}$.

[...] En la explanada rústica, en el suelo, se ven cajas de pasas vacías, cuarterones, formaletes, fruteros colmados de pasas, un carro sin bestias, aperos de labranza contra la pared, dos jaulas con perdices, capachos, arados, viergas de trilla, todo lo cual compone un magnífico cuadro campestre [...] $\mathrm{Al}$ alzarse el telón viene de derecha a izquierda la cuadrilla de vendimiadores uno detrás de otro, con los fruteros a la cabeza llenos de uvas en forma de pirámides...

Rueda estaba orgulloso de su popularismo andalucista; basta leer, para comprobarlo, el artículo «Drama en coplas», Madrid Cómico n. ${ }^{\circ}$ 558 , de 28 de octubre de 1893 . Se propone nuestro poeta demostrar «que en cualquier puñado de coplas elegido al azar hay encerrado un drama», y lo consigue ensartando buen número de ellas.

No significa esto que sólo haya popularismo en los libros mencionados. Citaremos los poéticos en otros contextos; en cuanto a los narrativos, téngase en cuenta el tono fantástico y sobrenatural de relatos como «La boda de espectros», «El entierro del rayo de sol» o «El alma en pena» de Tanda de valses.

75 Madrid, Impta. de El Crédito Público, 1889.

76 La corrida de toros descrita por Salvador Rueda, Madrid, E. Gutiérrez y Cía., 1889.

77 Madrid, Tipogr. M. G. Hernández, 1890.

78 Madrid, Gran Centro Editorial, 1891.

79 Madrid, La Novela Corta, año VI, n. ${ }^{\circ} 280,1921$.

80 Id., año IV, n. ${ }^{\circ} 174,1919$.

81 Madrid, Soc. Autores Españoles, 1903. Cito por Los Contemporáneos, año XIV, n. ${ }^{\circ} 682,1922$.

82 Op. cit., pp. $19^{-} 10$. 
El filosofismo prosaico de Rueda, más propio de un seguidor de Núñez de Arce y Campoamor que de un modernista, es otra constante digna de atención. El poema «Arcanos» de Noventa estrofas, dedicado a Núñez de Arce y escrito en tercetos encadenados, evoca la pérdida de la paz e inocencia de la niñez, las miserias y mezquindades de la vida, las pretensiones de sabiduría y el desencanto final del hombre.

En tropel contiene abundantes poemas de este tipo. Por el «Aquelarre histórico» desfilan Mitrídates, Safo, Cleopatra, Helëna de Troya, Mesalina, Isabel la Católica, Dante, Julieta, Rossini, Felipe II, Napoleón, María de Ágreda y Baco, en una especie de estrafalario Drama universal en dodecasílabos monorrimos, que tiene su eco en «La orgía de esqueletos» del mismo libro. Fornos ${ }^{83}$ relata la triste historia de un andaluz licenciado en Derecho que va a Madrid a doctorarse. Junto al coloquialismo vulgarista, la ramplonería es omnipresente, y evidentísima la influencia de Campoamor. El poema comienza así:

Metido entre las sábanas del lecho, no presa del ensueño o del marasmo sino mirando pensativo el techo y latiendo de vida y de entusiasmo

La sorpresa del mozo aldeano ante la gran ciudad merece los siguientes versos:

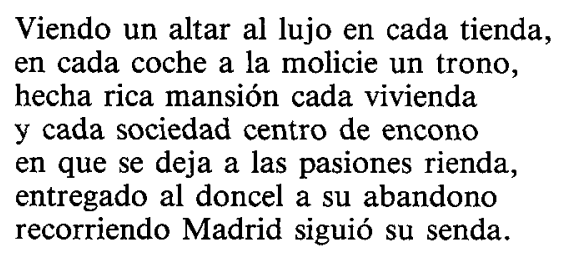

Finalmente, el pobre doctorando cae en el vicio y llega al encanallamiento sumo y muere, consumido por el alcohol y las mujeres; la moraleja es que Madrid se ha vuelto «la cloaca mayor que hay en el mundo».

El bloque ${ }^{84}$ parece el equivalente en verso de la base de algún monumento a un prohombre como Castelar o Cánovas. Desfilan en él las razas humanas desde la Torre de Babel y el arca de Noé, y los grandes

Fornos. Poema en seis cantos, Madrid, Tipogr. M. G. Hernández, 1896.

84

El bloque. Poema, Madrid, Impta. Hijos M. G. Hernández, 1896. 
Imperios de la Antigüedad (Egipto, Babilonia, Persia, Roma). El Cristianismo es cantado como culminación de la Historia en manos de la raza latina, cuyas glorias ensalza un desfile de profesiones de toda laya (políticos, periodistas, comerciantes, militares, banqueros, labriegos, poetas). Completa el cuadro un panegírico del progreso, del teléfono y el telescopio.

Flora ${ }^{85}$ es otro ejemplo de disparate, prosaísmo y vulgaridad. Historia de la mujer que da título al libro, «mitad valenciana, mitad mora», que se dedica a la prostitución. En una de sus orgías logra introducirse su padre, un mendigo a quien ella ha abandonado y que le inculcó en la infancia las ideas religiosas que al fin acabarán triunfando en el corazón de la pecadora. Flora es internada en la casa de arrepentidas de las micaelas; al entrar en la iglesia de la institución y ver a sus antiguas cofrades cantando la Salve, Flora renuncia a su vida pasada y aprende el oficio de bordadora. Ofrece a la Virgen una casulla cortada en su mantón de meretriz y sale del convento en busca de su padre; tras recorrer los peores tugurios de Madrid lo encuentra moribundo, se abraza a él,

Paso por alto los frecuentes deliquios religiosos y la insistencia en la tecla costumbrista en los parlamentos de presos y hampones.

Tropezamos con el filosofismo que reprochaba Rubén a Rueda en 1899 en varios poemas de Camafeos $^{86}$ ( «El yunque cerebral», «Al Nazareno», «Los alambres eléctricos», «La fotografía» —estos dos últimos, pedestres glorificaciones de la técnica), de Fuente de salud ( $\ll \mathrm{La}$ ciudad de hierro», visión de la metrópolis futura de la segunda revolución industrial, «Los pavos reales», «La granada»). En «El puente colgante» de Trompetas de órgano, en alejandrinos, el puente, símbolo de la servidumbre y grandeza de la civilización moderna, se derrumba al ser cruzado por un ejército de profanadores, saqueadores y violadores; Rueda entona como responso un canto al pacifismo. «El hombre químico» de Lenguas de fuego es una epopeya titánica del funcionamiento

85 Flora. Poema religioso en seis cantos, Madrid, Impta. Hijos M. G. Hernández, 1897. 
de la máquina biológica humana. El César ${ }^{87}$-el título designa paradigmáticamente a los políticos corrompidos- ataca la hipocresía y falta de valores cívicos y morales de la sociedad contemporánea y saca a escena las elecciones amañadas, la represión de las manifestaciones obreras, el caciquismo y el fraude electoral. El poema termina con la muerte del mal político a manos de la muchedumbre y la incitación declamatoria a la regeneración española. A pesar de su título, La procesión de la Naturaleza ${ }^{88}$ es un alegato contra la corrupción y vicio de la cultura urbana (simbolizada en este caso por París), a la que se contrapone un desfile igualmente simbólico de animales (tigres, ovejas, peces, abejas, camellos, insectos, avestruces, cóndores, pavos, leones, caballos, elefantes y serpientes) que representan la esperanza de un retorno purificador a lo natural y vital.

No quiero dejar de señalar que el filosofismo obsesivo de Rueda deturpa muchos textos que una referencia o lectura superficial podría hacer suponer de militancia modernista. En «Los pavos reales» de Fuente de salud se nos ofrece una lograda descripción preciosista («revestida de arrebol/ como de oro la corola/ de un redondo girasol/ parece su inmensa cola/ una pantalla del sol») que, sin embargo, viene lastrada por un fondo de fábula campoamoriana: un pavo real hembra cree que otro semejante pintado es su «amante esposo». La deseperación de la hembra cuando sus arrumacos no obtienen respuesta sirve para disparar la moraleja final:

El ave, igual que la mente, viven [sic] de ilusión en suma.

He mencionado en tercer lugar entre los deslices de Rueda su mitología rural, porque se reduce a la descripción de flores, frutas, insectos o animales, en un clima de exaltación rústica de la vitalidad elemental. A este respecto se podrían citar numerosos poemas de Cantos de la vendimia, «A dormir» de Camafeos, el conjunto de cuatro sonetos (al melocotón, las uvas, los higos chumbos y la sandía) titulado «Frutas de España» o los romances de la sección «Vidas con alas» (a la abeja, el abejorro, el escarabajo, la libélula, la cigarra) de Fuente de salud, «Los claveles reventones» de Trompetas de órgano o la ya citada Procesión de la Naturaleza. 
Las sensiblerías alcanzan su cota máxima en Flora, pero no faltan en otros libros del autor como Camafeos (los tres sonetos de $\ll$ Despedida a mi madre», «Beso eterno», «A mi hermana en la muerte de su hijo») o Trompetas de órgano («Viejecita mía», «La tísica»).

Los disparates y chuscadas son innumerables en Rueda, y no puede evitarse la sonrisa y en ocasiones la carcajada al verlo dar tan a menudo de bruces en ellos, con la contumacia propia de su irremediable aldeanismo. No encuentra, en el «Aquelarre histórico» de En tropel, mejor compañero de baile para «La Reina Católica, solemne y augusta» que «un gitano de faz patilluda»; y en este mismo libro dedica un poema grotesco nada menos que a «Los pájaros fritos»:

Ya en la cocina puesta la caza brilla
en pirámide inmensa junto a la hornilla,
despójanse las aves de sus primores,
sus túnicas brillantes de mil colores
..............................................
El otoño, amor mío, llegó corriendo
y los pájaros fritos lo están diciendo;
son una golosina que me enamora
y que gusta comerla con quien se adora
..................................................
y en el plato, que sirvan a mis amores,
para ti iré buscando los ruiseñores.

Cuando Rubén Darío quiso evocar parecida situación escribió aquello de «tus dedos divinos/ me dieron las fresas y los langostinos». El contraste con un lebrillo de ruiseñores (!) fritos no puede ser más radical.

Fornos, El bloque, El César, son en su totalidad monumentos a la vulgaridad y la ramplonería. Lo es llamar «ave selecta y elegante» al pavo real en «Los pájaros» de Piedras preciosas, y decir, en «A media noche» del mismo libro:

los sauces melancólicos se inclinan dando extrañas y lentas cabezadas.

Lo es, en «Las alas», imaginarse el poeta dotado de tales apéndices, haciendo la rueda como un pavo y diciendo a su amada:

... como velo de tus gracias sumas en tu balcón abriéranse sus plumas brillando al sol como gentil persiana.

Y lo es, en «Mi ideal», ofrecer el poeta a una mujer «mi lecho en que la gloria se divisa», sin duda por obra y gracia de sus poderosos atributos masculinos. 
Pasemos por alto El clavel murciano. Me parece impropio, en Trompetas de órgano, poema «A mi madre», tanto el dodecasílabo de seguidilla como expansiones como ésta:

Tu lírico sepulcro de verso y lloro sostendré en diez columnas que hará mi estilo con diamante, ónix, pórfido, turquesa y oro, carbunclo, ágate, jaspe, sardio y berilo.

¿Y qué juicio ha de merecernos el comparar Rueda a Sarah Bernhardt con una locomotora, en el poema que lleva por título el nombre de la actriz en Fuente de salud? ¿O estas palabras puestas en boca de Venus en su «Discurso» del mismo libro:

Si Venus Afrodita hablase un día
dijera así: Sed, pechos maternales,
sagrados y serenos manantiales
de paz, de amor, de leche y de poesía?

No creo que se hermanen bien la paz, la poesía y la leche. No terminan aquí las sorpresas deparadas por Fuente de salud; contiene un poema dedicado a «La musa de la cerveza», otro a «Cartagena» y un tercero a «La paella».

La cerveza, en opinión de Rueda, «va uniendo corazones por todo el mundo». Ello ocurre «en Nueva York grandioso como en Atenas/ en París esplendente como en la Nubia». No falta en el poema un exótico toque oriental:

Quizás también en suelos alcatifados y encima de almohadones de sedas vanas tiene un sultán los ojos encandilados en un baile de hebreas y circasianas.

Y cuando «la sed de sangre quema su boca», el sultán, en vez de ordenar una degollina de esclavas gordezuelas, como hubiera deseado todo lector, se bebe una cerveza.

No tengo nada contra Murcia, al contrario, pero me parece algo excesivo y subido de tono este elogio de Cartagena:

Te traigan por presentes ricos y varios

Arabia sus inciensos y dromedarios,

Venecia venga en góndolas a ver tu edén,

te dé un mantón de flecos Andalucía,

rosas de cien mil hojas Alejandría

y ardorosos rosarios Jerusalén. 
Venga para admirarte Rusia nevada en pieles de osos blancos arrebujada, traiga Manila conchas de su confín, el Sur sus pavos reales de manto bello, y el Norte un blanco cisne de largo cuello donde forrado en plata venga Loengrín.

Te mande Persia un velo como un tesoro, te brinde Egipto un ánfora con asas de oro, un peplo hecho de encajes traiga Alençon, y un biombo con aves y quitasoles ardiendo en policromias y tornasoles a tus ojos de alondra mande Japón.

El gárrulo soneto a la paella pondera las cualidades alimenticias de este plato regional valenciano y se hace eco del entusiasmo con que lo engulle el hambriento:

y mientras traga el rico condimento, ¡Salve, rey de los platos!, vocifera.

He dejado intencionadamente para el final, en este breve repaso de los disparates y bizarrías de Salvador Rueda, el poema «Hora de fiebre» de Lenguas de fuego. En una horchatería valenciana el poeta entabla conversación con una opulenta camarera y la invita a sentarse a su mesa. Oigamos la historia en sus mismas palabras:

Miro alzarse regia en el ambiente y a mí venir mujer esplendorosa nacida en la Albufera valenciana. Parece una canéfora

de dalias blancas y claveles blancos, de arroz con palidez interesante, de nardos aromosos y de espléndidas magnolias señoriales se creyese estar formada la mujer magnífica que pone el vaso en la marmórea piedra.

La invito a que se siente, fascinado, y frente a mí colócase la diosa de cuya bata, entre las rojas cintas mal enlazadas, turbador blanquea el nidal de los cisnes soberanos de sus senos triunfales y redondos. Digo una andaluzada porque ría su cuerpo de incensario, que derrama vaho a naranja y a clavel y a fresa palpita estremecido por la risa.

y los dos senos de enfloradas cumbres 
saltan por fin del ceñidor de blonda.

Veloz quiero ayudar a la hermosura a recoger las trémulas palomas poniendo mano en sus sedeñas alas, pero una bofetada resonante, rotunda como un golpe de marfiles en el tapete del billar, estampa la valenciana insigne en mi mejilla.

En venganza, y para aplacar sus ardores, el poeta propina a la canéfora-horchatófora un enorme bocado en un brazo.

La experimentación con el verso y la estrofa es otro de los rasgos distintivos del Modernismo, declarado por Herrera y Reissig ( «Conceptos de crítica» ${ }^{89}$ ), Rubén ( Ricardo Palma» ${ }^{90}$, prólogos a Prosas profanas y Cantos de vida y esperanza) o Manuel Machado («Los poetas de hoy», en La guerra literaria ${ }^{91}$ ). La crítica lo ha puesto repetidas veces de manifiesto ${ }^{92}$. Rueda usa el dodecasílabo de seguidilla desde Renglones cortos y comienza a experimentar con versos superiores al alejandrino desde Noventa estrofas. Sinfonía del año es un sistemático esquema de variaciones métricas y estróficas que, por la singularidad que posee en imagen y rima, hubo de servir de inspiración tanto a Valle-Inclán como al primer Lorca. La experimentación prosigue en Cantos de la vendimia, Camafeos, La procesión de la Naturaleza, La Escala ${ }^{93} . .$. , Rueda se propuso conscientemente renovar de raíz el verso español, y lo consiguió plenamente (empleo del eneasílabo, del dodecasílabo simétrico y de seguidilla, del hexa, hepta y octodecasílabo, de series polimétricas, de series de verso blanco, del soneto con metros insólitos...) y manifestó además poseer al respecto un pensamiento teórico que veremos más abajo. La limitación que puede encontrársele en cuanto a pausa y acento se puede ver en la primera parte de este trabajo, en su enunciado por Cossío.

91 Ed. cit. pp. 97-117.

92 del mismo, Los poetas en sus versos, Barcelona, Ariel, 1973, pp. 199-231; E. Díez Echarri, «Métrica modernista», Revista de Literatura, 1957, pp. 102-120. 
El Modernismo literario, como el Prerrafaelismo, gustó de refugiarse en un mundo imaginario de halagos exóticos, preciosistas y eróticos, condensados con precisión de catálogo en «Divagación» de Rubén Darío, y de cuyo talante espiritual informa certeramente «La última ilusión» de Julián del Casal en su soñada visión de París ${ }^{94}$. El erotismo y los temas grecolatinos aparecen en Salvador Rueda, junto a otros elementos propios de la aristocracia mental modernista (prescindo de los temas orientales por ser de filiación y raigambre menos decisorias).

Habría que citar los sonetos de la serie La bacanal ${ }^{95}$, trasplantados posteriormente a Camafeos y Lenguas de fuego, de ambientación romana y báquica; los veintiún sonetos de la serie «Mármoles» de Piedras preciosas (típicos en su recreación de obras de arte como el Moisés de Miguel Angel, la Venus de Médicis, la Victoria de Samotracia, el Laocoonte,la Venus de Milo, el Torso de Belvedere...), algunos poemas de Fuente de salud («La risa de Grecia», «Las metopas griegas», «El cisne») o Trompetas de órgano («El discurso del dios Pan», «El friso del Partenón»), y los dedicados a animales exóticos en La procesión de la Naturaleza. En todo caso, la superficialidad del descriptivismo de Rueda suele resultar decepcionante. Y sorprende encontrar, junto a los cisnes y pavos reales, un poema a los patos y otro al faisán (un faisán guisado en la cena del día de Reyes) en Fuente de salud. Por su parte, el erotismo de Rueda suele ser elemental y desprovisto de connotaciones culturalistas; léanse «Seno de mujer» de Lenguas de fuego o «Trompetas de órgano» del libro del mismo título. Destaca la obsesión de Rueda por el

doble glóbulo de fresa coronando los dos melocotones

que, bajo diversos disfraces retórico-frutales, aparece tan a menudo en sus páginas. Ya dimos antes alguna muestra de la garrulería que acecha al Rueda erótico; y es de justicia poner de manifiesto que La cópula ${ }^{96}$, salvo en algún detalle sin importancia, es un hermoso cuento oriental de elegante y rica factura, en mi opinión el mejor libro de Rueda en todos los géneros que cultivó.

94 J. O. Jiménez (ed.), Antología crítica... pp. 230-234.

95 Madrid, Tipogr. Hijos M. G. Hernández, 1893.

96 Madrid, Impta. J. Rueda, 1906. 
Finalmente, habría que atribuir al Modernismo el rechazo de la sociedad contemporánea y de sus valores científicos, financieros y fabriles, pero no en forma de protestas explícitas de carácter ideológico sino mediante la construcción evasiva de un mundo fuera del tiempo y el espacio real, que alcanza su culminación en el símbolo de símbolos, el color azul ${ }^{97}$. Recordemos la condena de la ideología modernista por Marinello y Françoise Pérus, entre otros ${ }^{98}$, y su reivindicación por Octavio $\mathrm{Paz}^{99}$.

A este respecto, Rueda oscila entre la admiración propia de un cateto hacia los avances de la ciencia y la técnica y la condena explícita, en tonos tribunicios de protesta social, de la civilización urbana. Ni una cosa ni la otra corresponden a la actitud modernista. De la primera tenemos ejemplos en «Los alambres eléctricos» o «La fotografía» de $\mathrm{Ca}$ mafeos, «El tren» de Trompetas de órgano, El bloque, «El Viaducto de Alcoy» y «Visiones nuevas» de las citadas Completas ${ }^{100}$. De la segunda, en «Arcanos» de Noventa estrofas, «Lo que no muere» de Estrellas errantes, «El guardavía» de En tropel, «El puente colgante» de Trompetas de órgano, Fornos, Flora o El César. Lo mejor que escribió Rueda en este registro temático es La procesión de la Naturaleza (salvo el «Preludio»). Alguna vez empleó el azul simbólico, como en «El lago ideal» de Fuente de salud:

\footnotetext{
Hay dentro de mi ser un terso lago todo luz, todo amor, todo pureza; de entre sus ondas saco la belleza y la armonía de su ritmo vago.
}

Veamos, para terminar, las ideas teóricas de Rueda. En ocasiones se expresan no en prosa ensayística sino en forma de poema. Así ocurre

97 Véase G. Allegra, Il regno interiore, Milán, Jaca Book, 1982; H. Hinterhäuser, Fin de siglo. Figuras y mitos, Madrid, Taurus, 1980; L. Litvak, Transformación industrial y literatura en España (1895-1905), Madrid, Taurus, 1980; I. Schulman, «Génesis del azul modernista», en $\mathrm{H}$. Castillo (ed.), Estudios criticos sobre el Modernismo, Madrid, Gredos, 1968, pp. 324-357. Véase también «El lago de Pátzcuaro» de Gutiérrez Nájera en J. O. Jiménez (ed.), Antología crítica..., pp. 132-136.

98 J. Marinello, Sobre el Modernismo. Polémica y definición, México, UNAM, 1959; F. Pérus, Literatura y sociedad en América Latina: el Modernismo, Madrid, Siglo XXI, 1979.

99 «El caracol y la sirena», en Los signos en rotación, Madrid, Alianza, 1971, pp. 88-102.

100 Op. cit., pp. 133-135 y 264-267. 
en «Lo que no muere» de Estrellas errantes, «El acento en la poesía» de Trompetas de órgano, y «Lenguas de fuego», «El verbo-órgano» y «Auto-bio-crítica» de Lenguas de fuego.

En el primero de estos poemas lamenta Rueda la degradación de la poesía, que ha perdido el espíritu propio de la Antigüedad clásica; pero aunque la época moderna suponga la muerte del ritmo, el color y la música, el espectáculo de la Naturaleza y los sentimientos elementales del ser humanao los mantendrán vivos. El segundo expone las cualidades de la estrofa bien compuesta, que ha de ser equilibrada como el conjunto de pétalos de una flor:

Un clavel de llamas es una poesía, una unión de pétalos, un ritmo acordado;

ni un acento rompe su gran melodía, ipues son los acentos de origen sagrado!

En el tercero pondera Rueda la sinceridad vital y el impacto sensorial de sus versos; lo mismo en el cuarto. El quinto reitera las ideas ya expuestas de Ugarte acerca de las características de una literatura legítimamente hispanoamericana:

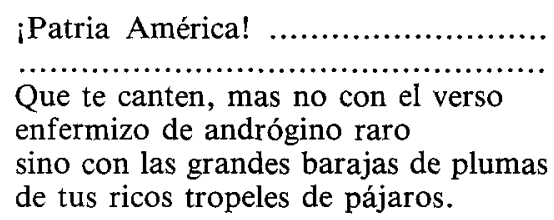

En Madrid cómico de 11 de julio de 1891 publicó Salvador Rueda «Gatos y liebres», breve texto en prosa sin más sustancia que lamentar la testarudez y miopía de los poetas y críticos que siguen aferrados a la poesía posromántica, heroico-cívica y de circunstancias. La Revista Nueva de 1899 incluye «Dos palabras sobre la técnica literaria» ${ }^{101}$ dedicadas a Unamuno, de parecido propósito:

Nuestros literatos, por lo general, toman el idioma por una serie de planicies petrificadas y escriben al modo retrógrado, es decir, volviendo a remedar tal o cual momento por el que pasó nuestra lengua, y así vera usted que en vez de labrar el idioma por el momento en que va haciéndose, cometen la cobardía de abandonar el tajo de labor e irse a tiempos pasados de las letras [...] La labor general consiste [...] en formar un anillo más de esa culebra viva y ondeante, cuerpo vivo como el nuestro, que se llama idioma de una raza.

101 Vol. I (15 de febrero a 5 de agosto 1899), pp. 729-734. 
En tropel lleva un epílogo en prosa, «Color y música», en el que Rueda pone de manifiesto la relevancia de esos dos ingredientes del lenguaje poético. Pero sus ideas fundamentales se encuentran en El ritmo ${ }^{102}$. Octosílabo y endecasílabo son las dos lacras de la poesía tradicional; existe una acuciante necesidad de renovación de metros y estrofas. Rueda se propone demostrar que, a diferencia del petrificado lenguaje poético convencional, el habla común utiliza infinitas combinaciones métrico-acentuales susceptibles de ser poetizadas. Para demostrarlo escoge un párrafo del editorial de El Liberal de 2 de septiembre de 1893, lo fracciona en segmentos y escribe un poema sobre la métrica y el ritmo impuestos por cada uno de esos segmentos. En consecuencia, todos los metros son igualmente dignos y poéticos; no existe limitación en cuanto al número de sílabas del verso más allá del alejandrino; y cada metro puede a su vez modularse variando el esquema acentual. Rueda es tajante en sus condenas y remedios:

¿No cree usted que se haya dado al traste con nuestro tímpano y que el oído esté reclamando con gran urgencia metros distintos, ritmos nuevos, estrofas [...] Se me puede objetar también que muchos de los metros de que está compuesto cuanto se habla y se escribe no son dignos, no son bellos: error; todos son igualmente dignos y bellos, pero es cuando los trate un poeta de inspiración, de gusto, de genio... ${ }^{103}$

Lleva $E 1$ ritmo un epílogo de críticas; la más interesante es sin duda la dedicada a Efímeras de Francisco de Icaza, en su elogio de la paciente y concienzuda labor de orfebrería a que debe entregarse el poeta, de acuerdo - dice Rueda- con la enseñanza de los Parnasianos. Carecen de interés teórico el soneto que prologa Luchas de Villaespesa ${ }^{104}$, el preliminar a Canciones rebeldes de Linares Becerra ${ }^{105}$, el atrio a la sección «La hoja de hierro» de Trébol de Alcaide de Zafra ${ }^{106}$ y el prólogo a Diálogos fantásticos de Martínez Sierra ${ }^{107}$. El artículo «Los melódicos y los instrumentales», en El Nuevo Mercurio de febrero 1907, pp. 161-170, expone ideas similares a las de Manuel Ugarte. En los últi-

102 Madrid, Tipogr. Hijos M.G. Hernández, 1894.

103 Op. cit., pp. 15 y 52.

104 Madrid, Impta. C. Apaolaza, 1899.

105 L. Linares Becerra, Canciones rebeldes, Madrid, Impta. R. Velasco, 1908.

106 J. Alcaide de Zafra, Trébol, Madrid, Tipogrs. J. Palacios \& R. Hernández, col. Iris, 1899.

107 Madrid, Tipogr. A. Pérez \& P. García, 1899. 
mos años de su vida, en carta de 27 de marzo de 1925 a Narciso Alonso Cortés, recapituló Rueda su aventura creativa y sus resentimientos de olvidado. Se jacta en ella de haber enriquecido la lengua poética con innovaciones métricas y léxicas (términos tomados de las ciencias y el habla coloquial y rústica), de haber adaptado en castellano el hexámetro y de su amor al mundo griego. En esto último resulta patético, tanto como al escribir Verlén o Bodeler:

Vienen estas devociones mías al alma griega de mis muchos años tran'scurridos como archivero, bibliotecario y arqueólogo del Estado español en el Museo de Reproducciones Artísticas de la Corte...

¡Pobre Salvador Rueda en su Grecia de escayola! Nunca le perdonó a Rubén ni el éxito ni el desdén:

Y después de mi entrada desde los campos a las ciudades, simbolizadas en Madrid, después de infiltrado por la poesía y por la literatura el espíritu de la vida, fue cuando primero Asunción Silva de Colombia, Julián Casal de Cuba, Gutiérrez Nájera de Méjico y, por último, Rubén Darío de Nicaragua trajeron, más éste que los anteriores, otro tren cargado con la decadencia [...] Todo ese bagaje libresco, todo ese vicio de cultura, detritus decadentes, cayó sobre la salud de mi invasión de Naturaleza [...] Darío, mi camarada en el vivir literario de la Corte, lo traía todo empaquetado y listo de Francia, como las corbatas, y no se desprendió jamás ni para dormir de su Diccionario de la rima [...] No se asomó jamás con el cerebro ni a la ciencia ni a la Vida, y carece de contenido cerebral, de contenido emocional y de contenido moral [...] Darío era un hombre que ni en su conversación, completamente mate y vulgar, ni en hecho ninguno de su vida revelaba el menor asomo de poeta... ${ }^{108}$.

Un año antes de morir estampó Rueda El poema del beso ${ }^{109}$; como en un testamento, condensan algunos poemas ( Pregones al viento», «El fuego de las piedras», «Las metamorfosis») su vitalismo cósmico, elemental y erótico; aún es capaz de escribir excelentes sonetos como «El fumadero de opio»:

Verdosos tornasoles boreales alza el mar de Ceylán, y anestesiada

Colombo sueña, sueña rodeada

de ondas como fosfóricos cristales.

Carga pipas de tóxicos fatales

la Cocó, bailadora engalanada

con sus trajes simbólicos, y armada

de pupilas cual pérfidos puñales.

108 Art. cit., II. pp. 159 y ss.

109 Madrid, autor, 1932 . 
Ritmos dorados danza peregrina

de éter y pantopón, de opio y morfina, que en giros atrayentes encadena.

Al que miran sus ojos languidece;

al que estrechan sus brazos lo envilece;

al que besa su boca lo gangrena ${ }^{110}$.

Poco dejó de valor a su muerte, a tenor de los inéditos publicados en $1957^{111}$.

Como resumen de este largo viaje por la obra casi completa de Rueda, yo diría que lo vinculan al Modernismo el preciosismo de su lenguaje, sus experimentos con el metro y la estrofa y el uso de algunos ingredientes exóticos. Lo alejan de él la falta de cultura, el mal gusto, la vulgaridad, la superficialidad y el filosofismo prosaico. Se trata de una contradicción insoluble.

110 Op. cit., p. 85.

111 Claves y símbolos, Málaga, Caja de Ahorros Provincial, 1957. 